\title{
An Overview of Social Work Practice in Health Care Setting with Special Reference to Pakistan
}

\author{
Dr. Syeda Farhana, \\ Assistant Professor, Dept of Social Work, University of Karachi \& \\ Clinical Social Worker/Psychotherapist \\ Dr. Sakina Riaz \\ Assistant Professor, Department of Social Work, University of Karachi
}

\begin{abstract}
This paper describes the overview and historical development of social work in the health care system with special reference to Pakistan. The main purpose of this paper is to understand how social work is deliberated and executed in Pakistan. What are the challenges and administrative problems faced by social workers in this field? This study is exploratory research and researcher employing qualitative methods to explore this issue. The paper covers, three major areas, i) provides a brief world view of social work in health care, ii) role of social work in the health system and its relevance, and iii) the historical development of social work in health care in Pakistan. An endeavor has been made for in-depth analysis of the numerous aspects of exist and identify the problems and prospects of Social Work in health care (medical social work) as a profession in Pakistan and derived some viable recommendations for better prospects.
\end{abstract}

Keywords: Health care, medical social work, social health determinant of health, health inequalities, Pakistan.

DOI: $10.7176 / \mathrm{JESD} / 10-14-17$

Publication date:July $31^{\text {st }} 2019$

\section{Introduction}

Social work has an old discipline, has its distinctive combination of theory, and filed work practices. This uniqueness marks this profession as extraordinary distension in the field of social sciences.

The aim of professional social work is to lead the human being into a successful life on 'self-help bases' with freedom and independence. This discipline is more than 100 years old, and has a well-developed system of professional education governed by national educational policy and accreditation standards (Council on Social Work Education, 2006). Social workers use a variety of skills, techniques to assist individuals in making and sustaining positive change. As adviser, advocate, counselors, a social worker helps people to live more successfully within their local communities by helping them find solutions to their problems.

The profession of social work was built upon an acknowledgement that individuals, families, groups and communities interact with their environments and are shaped by them. Individuals do not operate in isolation but are influenced by their physical and social environments in which they live and interact. Social work practice involves taking into consideration a person and the environment around her or him and is referred to as the "personand-environment concept". (Gitterman \& Germain, 2008)

Social workers work in hospitals, community clinics, and other healthcare settings to support patients and their families, and to assist the larger medical team in the coordination of patients' care. They play an essential role in many of the non-medical aspects of patient care, including helping patients and their families navigate the medical system, assessing and monitoring patients' and family members' mental and emotional health, providing short term counseling and therapy, and communicating patient needs and concerns to the larger medical team.Social workers, work closely with patients and family members who are experiencing mental, emotional, family, and/or financial stressors due to their or their loved one's medical condition. The social worker employed in hospital setting in generally "Medical Social Worker" who work for the betterment of the patient from admission to the discharge but also offered the post discharged follow-up services and home visits.

Hence, Medical social work offers a variety of service to patients and families within the hospital.They help people who are suffering with a medical problem, works with clients/patients and their families to provide necessary services for making their lives easier specially in illness duration and help them to deal with the consequences directly related to illness. Medical social workers play an important role in linking up the medical and social services for facilitating patient's speedy recovery and rehabilitation in the community. Moreover, Medical social workers are very helpful in facilitating the Patient's paperwork and provide guidance to the family through the entire process of patient admission, hospital stay till their discharge from hospital.

The main purpose of this paper is to understand how social work in general and social work in health care system in specific is designed and implemented in Pakistan. What are the challenges and what are the administrative problems faced by professionals? Employing qualitative methods this paper is exploratory in its nature. 


\section{Western Concept of Social Work in Health Care System:}

Globally, medical social workers report an increase in the severity of client problems, huge case-load, paperwork and waiting lists for services (Whitaker, et al., 2006). Due to the workload, for a doctor or a nurse, it is not possible to solve the patient's psycho-social or sometimes economic problems. It's, therefore, the medical social worker who play a vital role in handling patients these needs effectively and efficiently.

Initially, the prerequisite of social work practice in the health sector was first felt in England in 1885, when discharged patients of mental hospitals needed aftercare in their homes to avoid recurrence of their illness. Doctors and nurses widely felt the need to follow up the cases discharged from mental and other hospitals. All the time they were experienced with those patients who recently released from hospitals. They realized that they were coming back to the hospital as they were affecting again when they were returning to their environment. the feeling grew that these people needed help with their economic and social problems which came in the way of their recovery (Dastur,R., 1974 ). They strongly felt that home visit and aftercare is needed for their holistic care. In 1905, Dr. Richard Cobat (Cobat 1928) introduced the Medical social work at Massachusetts General Hospital in Boston.

The social worker's in the health care system, as "sanitary visitors" in the US- took note of income, living conditions, education, and employment. Early training of US physicians and nurses included home visits. UK social workers first called "almoners" referring to work with the poor. The role was to "screen by a competent person of education and refinement who could consider the position and circumstances of patients" (Gehlert \& Brown, 2012).

"The social worker seeks to remove those obstacles, either in the patient's surroundings or in his mental attitude, that interfere with successful treatment, thus freeing the patient to aid in his recovery" (Ida Cannon, 1923) Treating the whole person: Social Work's primary role Person in Environment (Keefler, et al., 2001).

The healthcare systems in the western world were quite a bit different from one another, with some being completely privatized, some being public, and some being mixed systems, their overall systems and health outcomes from those systems were much more like each other. It is also important to note that the European countries historically all moved to more socialist healthcare systems relatively quickly during and directly after World War II due to the chaos and need for structural stability in the area (Mossialos, 2017).

It is evident that, there is a strong empirical relationship between living circumstances and health and social problems prevailing in the society in generals. Countries with the greatest wealth are not necessarily healthiest US spends more per capita than any other country in the OECD but has poorer health. The wider the income gap within a society the higher its mortality and morbidity rates (Wilkinson \& Picket, 2009). Medical care plays a limited role in reducing mortality in Western nations compared to increased income, nutrition and public health efforts (Moniz \& Gorin, 2010)

Health and social problems are a result of adverse living circumstances and these are shaped by public policy. Half of all healthcare outcomes are linked to the social determinants. Only $15 \%$ of outcomes are linked to biology and genetics, $10 \%$ of outcomes are linked to environmental factors, 1 in 5 healthcare dollars is spent addressing problems related to poverty. Action taken to reduce health inequalities will have economic benefits (Marmot, 2010).

At every stage in life, health is determined by complex interactions between social and economic factors, the physical environment and behavior. Research shows that the social determinants can be more important than health care or lifestyle choices in influencing health (Mikkonen and Raphael, 2010).

- Income and social status

- Employment and working conditions

- Education and literacy

- Childhood Experiences

- Physical environments

- Social supports and coping skills

- Healthy behaviors

- Access to health services

- Biology and genetic endowment

- Gender

- Culture

The World Health Organization suggests all nations establish policies and programs to:

- Improve the conditions of daily life.

- Tackle the inequitable distribution of power, money, and resources.

- Measure the problem, evaluate action, expand the knowledge base, develop a workforce trained in the SDOH (Social determinants of health).

- $\quad$ Raise public awareness about the SDOH (CSDH-WHO, 2008 ). 
Social determinants of health refer to a specific group of social and economic factors within the broader determinants of health. These relate to an individual's place in society, such as income, education or employment. Experiences of discrimination or historical trauma are also important social determinants of health for certain groups. Differences in the health status of individuals and groups are called health inequalities. These differences can be due to your genes and the choices you make. For example, whether you exercise or drink alcohol. However, the social determinants of health can also have an important influence on health. For example, people with higher incomes are often healthier than those with lower incomes.

Social and health indicators such as those used by the World Health Organization (CSDH, 2008) provide a way of comparing health and well-being. It means the social origins of health includes several key elements, such as biological factors, individual life-course, health inequalities and different social and physical environments that lead to health outcomes. The term Inequalities used to describe in the final report of the measurable differences in the health characteristics of individuals and groups.(CSDH, 2008)

Health inequity refers to health inequalities that are unfair or unjust and modifiable. For example, people who live in remote or underdeveloped regions do not have the same access to nutritious foods, health facilities education and other opportunities etc., as other people in the urban area.

Health equity is the absence of unfair systems and policies that cause health inequalities. Health equity seeks to reduce inequalities and to increase access to opportunities and conditions conducive to health for all. Early interventions from social worker always be tied to a social determinant and outcomes can be easily identified. As a part of healthcare ally the intervention has the potential to improve health/quality of life and/or reduce the number of interfaces with the health care system.

It is evident that, attention can lead to improved quality of life, reduced psychological stress and improved physical health. Identifying potential resources and services, discussing them with the client and facilitating referrals are important functions for social work and fulfill one of social worker's key role: linking people to resources (Hepworth, et al., 2002).

The global scenario is changing regarding health as well, according to the Global Burden of Disease Study 2010 (Lim, et al., 2012), that the significant changes have been identified in mortality within an ageing worldwide population; there are now significantly fewer child deaths from malnutrition (with the exception of parts of subSaharan Africa); however, there are significant increases in chronic illness, disability and mental health conditions and injuries. These are key domains for social work practice too.

Regulation of a profession such as social work, which operates in highly contested legal and ethical environments, provides the public, other professions and all stakeholders with clarity about the standards of practice and behavior and of professional ethics which can reasonably be expected (Jones, 2018).

Statutory social work regulators now exist or are being actively explored in several countries (Palattiyil, et al., 2015), including United States of America and Canada (American Association of State Social Work Boards 1998) , Kentucky Legislative Research Commission 2012 (Diedrichet al., 2015), New Zealand (McNabb, 1988;Heugten, 2011), Zimbabwe (Sachiti, 2012), Finland (Talentia, 2016), Nigeria (Okoye, 2017), Japan (Iwasaki, 2001), Hong Kong (Leung, 2001; Jones 2007), Malaysia (Jones, 2007) and Australia (Nayor, 2001). In some countries the profession is more directly regulated by government (Hussein, 2011).

The regulation authority for social workers generally are working on protects the interest of the public by regulating the practice of social workers and promoting ethical and professional practice. These authorities usually serve and protect the public by:

- Setting entry-to-practice requirements to ensure that only those with specialized educational qualifications are eligible for registration.

- Setting, maintaining and ensuring that all members follow the Code of Ethics and Standards of Practice.

- $\quad$ Maintaining a Public Register of registered social workers (RSWs)

- $\quad$ Requiring members to engage in ongoing learning through the Continuing Competence Programs

- Maintaining rigorous complaints and discipline processes. (Hutchison, 1987)

These above noted regulations of a profession define the practice of the profession and describe the boundaries within which it operates, including the requirements and qualifications to practice the profession. The primary role of any regulatory is to protect the public interest from unqualified, incompetent or unfit practitioners through rigorous complaints and discipline processes. It brings credibility to the profession. The practitioners of a regulated profession are subject to a code of ethics and standards of practice and complete the Continuing Competence Program annually.

This self-regulation allows a professional act as an agent of the government in regulating its members because the government acknowledges that the profession has the special knowledge required to set standards and judge the conduct of its members through peer review. Western countries are putting the social determinants into action places of influence for social work and we can observe and identify easily, the difference of services in the following areas of health care: 
- Primary care

- Family Health Teams

- Community Health Centre

- Community Care Agencies

- Retirement/Nursing Homes

- Social Planning Agencies

- Community Mental Health

- Seniors Services Centre

- Hospitals especially ER/intake/discharge / community referrals/care plan

- $\quad$ 10-Health researches

There are several standardized developed social work documentation tools are using for patient psycho/socio assessment or screening. Accurate assessment is at the heart of effective social intervention because assessment involves "the thinking process that seeks out the meaning of case situations, puts the particulars of the case in some order and leads to appropriate interventions" (Meyer, 1993).

Social Workers as the "screener" for the SDOH on the part of the team environmental scan generally, where many social workers providing inpatient and outpatient care including trauma, ICU, rehabilitation, Family Health Teams, mental health services, cancer care, cardiac care and using these developed standardized assessment tools. These documents independently observed through chart audits, licensing authority (national/provincial college of social work and social services work) guidelines, many and varied consumers of information. The social work assessment content includes, demographics, relevant health information, financial situation, living situation/functional status, family/social/community, clinical impressions interventions/ recommendations.

Most physicians have their hands full providing medical care, and so, despite concerns about their patients, have limited time to address their social needs outside of the office. A social worker is in an ideal position to offer the supportive counseling, social service referral assistance, and advocacy that many need to regain some stability in their lives. Physicians (Family Doctors), social workers, and other health care professionals practicing together in a team-based model provide the 'wrap around' care that many patients truly need. As an example, at community health center, they refer certain clients to social worker to address issues holding them back such as high stress, poor coping skills, isolation, anxiety, depression and past trauma. Social workers are integral members of interprofessional models of care like family doctors' clinics or community health center.

\section{The Concept of Medical Social Work Practice in Pakistani Context:}

Pakistan, a country situated in the Southern part of Asia is the $6^{\text {th }}$ most populous country of the World, with its current population estimated at 156.26 million (Government of Pakistan, 1998) Pakistan is a developing country with a rapidly growing population. Pakistan, with a GNP of US \$ 470 per capita, central government expenditure on health is only about $1 \%$ (UNICEF, 1996). In recent years, especially after independence, Pakistan has undergone enormous changes politically, economically socially. These changes have brought a large amount of uncertainty within people's life. Providing better healthcare facilities are the primary responsibility of the Government. Provinces of Pakistan previously assumed overall responsibility for the implementation of health care services. Through a process of decentralization initiated in August 2001, however, districts began to assume responsibility for all public activities, including health care services. According to KhalidM. (1982):

"Centuries ago the idea of welfare state began to influence the state policy and action. In most cases, the state directly participates in the economic sphere. It controls and regulates wages, cost of living and prices, finances, credit, currency, foreign exchange, banking insurance, and several other matters are regulated and controlled for the benefit of common people."

The medical social worker must provide several services in health care set-up. According to Margaret Alston (2001):

"Social Worker assess the social circumstances of clients, establish the extent to which these have contribute to ill health, and alleviate these conditions; plan adequate care in community once people have been discharged from hospital; attend to those matters that may interfere with healthcare; and ameliorate the social distress, including of family and friend, caused by illness, disability, frailty, and death".

Medical Social Work has undergone significant changes in Pakistan since its inception (1947) and at that time, much of work was done upon the sponsorship or donations or on aid basis of Philanthropists (Mohammad Khalid, 2011). At the initial time of a newly independent country, the rehabilitation process of the migrated people, who were living in refugee camps in the un-hygienic environment, was the big target. Therefore, most of the time, the work was done on a haphazard basis and in emergency situations without any planning for concrete action. People involved in social service were un-trained, having a lack of expertise and they did voluntarily job and perform this duty on a humanitarian basis. According to Sherieen Rehmatullah (2002): 
"In 1953, Miss Anna Mo Toll, a Swedish, medical social worker visited Karachi, in response to the request from the Govt. of Pakistan to UN"

History had viewed that in early days of country's inception and people's rehabilitation in the new country, everyone was stunned about the meaning and scope of "Medical Social Work" and concerned about its accomplishment in a country. Some health officials even felt that there was no need to train people, especially for medical social work. (Rehmatullah, 2002; Malik \&Sarfaraz, 2012). Many donors were engaged in the welfare work without professional approach. With the passage of time, the situation has changed drastically and Medical Social Work has no longer highly dependent on the philanthropist and volunteers for funding. It has become a profession now although there is a strong alliance continues to exist in many cases.

Current Practices and Challenges for Medical Social Work as a Profession in Pakistan:

Access to health care is a basic human right(Ali,2000). This right is duly accepted in Article 25(1) of the Universal Declaration of Human Rights(UNO,1948; UDHP,1948; Youth for Human Rights International,2010).In Pakistan, $3.1 \%$ of the gross domestic product is spent on economic, social, and community services; $43 \%$ is spent on debt servicing. (Government of Pakistan,2002)About $0.8 \%$ is spent on healthcare, which is lower than in Bangladesh (1.2\%) and Sri Lanka (1.4\%) (World Bank, 1998/99) In 2005 and 2006, less than 17\$ was spent on each Pakistani's health, which is very low based on international standards (Poullier, JP, et al, 2003) Healthcare statistics shows that healthcare workers include 91,823 physicians, 37,623 nurses, 4,175 dentists, 22,528 paramedics, and 5,619 female health workers. There are 796 hospitals, 93,907 hospital beds, 5,171 basic health units, 531 rural health centers, and 856 maternity and child health centers (Government of Pakistan,2001) The Pakistani healthcare system is neither competent nor comprehensive to provide adequate services for the growing population. (Shariff KM.,2001).

In Pakistan, most of the people, live under poverty, are derived from health services due to lack of doctors and nurses. People are still unaware about healthy lifestyle and often their low economics background insists them to ignore their diseases at an early stage.

Medical Social work grew out of humanitarian and democratic ideas, and its values are based on respect for equality, worth, and dignity of all people. It focused on meeting human needs and developing human potential by enabling them to solve their problem on a self-help basis. Following are the details of the objectives of Medical Social Workers' job in the health care center.

Objectives of the MSW Services:

- To help the community assess their needs and organize the people to plan programs to provide services in order to meet the needs of the needy patients.

- To create social awareness in the needy patients particular and community in general about the social causes of diseases, their prevention, and amelioration.

- $\quad$ To organize groups of individuals to educate them to utilize available resources and tap resources to meet the needs of the patients.

- To assist in disability prevention and rehabilitation

This is an extremely complex process, which demands a systematic approach for developing the understanding of patient rights and their satisfaction. Globally, the scope of medical social work education, remunerative work, and community affairs are very demanding, especially in developed countries. However, in Pakistan, the profession is yet to gain adequate recognition from those individuals and institutions that matter.

An important challenge which faces to clinical social work practitioners in the country is that the situation of professional social work especially Medical social work is often in a poor stage. Although social work has been progressively recognized in some areas of Pakistan as a concept or as a profession, it is still felt by the masses as an act of 'good will' or charity inspired either by a sense of religious duty or simple piety.

In Pakistan, people have a habit to help the patient, visit them during their hospitalization. This practice is being considered as an important norm and moral obligation stems from Islamic ethical principles. Interestingly in Pakistani society, people often not easily differentiated between professional and non-professional social workers. Most of the people believe that there is no need for any expertise, skills or professional degree is require for doing social work. Anybody may practice or distribute charity, do reform work as a social worker. As a matter of fact, the professional identification and clinical license system are not working in the country for authorizing the people to work with in professional framework. Keeping view the above discussed administrative problems and confusion about the professional services of the worker, there should be a yard stick or professional recognitions of the social worker it is necessary to have a licenses system in the country.

There is a growing body of literature addressing the social determinants of health. Social forces acting at a collective level shape individual biology, individual risk behaviors, environmental exposures, and access to resources that promote health. Based on a holistic model, social workers use a bio psychosocial framework to approach assessment and intervention (Volland, et al., 1997). This framework considers biological factors (genetics, disease, chronological processes), psychological factors (perception, cognition, emotion), and social 
factors (lifestyle, culture, race and ethnicity, class, gender). Social workers deliver services to people encountering health challenges, even when health care is not the primary focus of the intervention. (Whitaker, et al., 2006)

Globally, the 21st Century promises extraordinary changes in health care, including dramatic increases both in the need for and in the utilization of, health care services. As the "baby boom" generation ages, the nation's health care workforce is anticipating a crisis that will extend beyond the current nursing shortage, affecting the availability of a range of health care professionals, including social workers (Wing \&Salsberg, 2002). In addition to addressing health care workforce shortages, eliminating disparities in health care has also become a national priority. Across the country, many people face barriers in their ability to access health care these barriers disproportionately affect people with low incomes.

Pakistan has one of the lowest rates of literacy in the world, among the comparative socioeconomic countries. In Pakistan, there are many issues in the health sector like low efficacy for implementation of programs and insufficient funds and budget allocation with poor management and lack of supervision. In the health sector, less budget allocation is causing great difficulties to meet the needy patients' requirement.

In Pakistan due to the increasing cost of living which leads to a number of social, emotional, psychological and economic problems which increased rapidly. The situation becomes more serious if somebody from the family gets hospitalized due to chronic illness because most people are living in the joint family setup. In Pakistan, like other developing or under developing countries, health care expenditure extends beyond the range of common man. The statistics on health performance of other South Asian countries suggest that Pakistan lags behind in infant mortality rate (at 63 per 1000 live births) and under 5 years mortality rate (at 86.5 per 1000 live births). These indicators continue to remain high mainly on account of unhealthy dietary habits, waterborne diseases, malnutrition, and rapid population growth. Similarly, a number of studies have appeared on the health situation in the country.(Bhutta,2011; Burki,2008;Lashari, 2004; WHO,2010;Zaidi,1988)K.Z.Hasan, wrote in his paper "Health of the Nation Present Status and Future Prospects"(1999), discussed the health situation of the country to be "grim".

\section{Present Situation of Medical Social Services in Sindh:}

According to Rehmatullah S. (2002) "People in Pakistan are charity-oriented organized as well as personal. This charity attitude had to be channeled and demonstrated as the only means of achieving."

Medical Social Welfare officers are employed in hospitals to cater the need of poor and vulnerable patients in hospital. In Pakistan, Medical social welfare officers generally with the help of hospital administration, doctors and eminent philanthropist, established Patient welfare society in Hospitals and collecting donation. The government also provides financial support from Zakat $^{1}$ Fund and Pakistan Bait-ul-Mal ${ }^{2}$.Zakat deduction was started in 1980. Later on, the system of Bait-ul-Maal was created from 'transfer of receipt from tax, grants, from the federal, provincial, and local authorities, organizations international agencies, voluntary donations including Sadaqat, and Kahirat ${ }^{3}$ (personal charities). It is broad and well-planned infrastructure of an Islamic Public Assistance System Developed which provides much needed support to medical social work at every level.

Mainly two types of services provided by social welfare officer like direct services to the patients (counseling services through individual casework approach).Direct services are provided directly to or for the client while indirect services performed on behalf the same population of potential clients.(Dubois etal.,2005)

However, in Pakistan, following are the salient features of Medical Welfare Services is to help individuals, couples and families to cope with the social, psychological, cultural and medical issues resulting from an illness, injury, accident or any mishap.

Medical social workers may help patients with advance directives and other long-term care issues. They assure that patients' medically related emotional and social needs are met and maintained throughout their medical treatment. As noted above, 3 major job responsibilities of Professionals Medical Social Workers in health care setting, which are:

- Provide Psychosocial Assessments to patients and their families.(Assessment of a person's problem solving, coping, emotional and developmental capacities in the context of their social and environmental circumstances;

- $\quad$ Group Work (Educational \& Therapeutic);

- $\quad$ Provide counseling services through individual casework or group;

\footnotetext{
${ }^{1}$ Zakat is a Religious obligation on every financially well Muslim to voluntarily pay to those Muslim who found in need.

2 Pakistan Bait-ul -Mal System (PBM) fulfills the aims and objectives of an Islamic Welfare State based on purely Islamic Tenants. In, Pakistan, in 1992 the Government set up Bait-ul-Mal, established as a separate body, a fund to provide assistance for the needy and destitute persons.

3 Personal charity provided to a needy person whether the person is Muslim or non-Muslim.

http://jamc.ayubmed.edu.pk/index.php/jamc/login
} 
- Working with families, facilitating family meetings; counsel the family members about patient's health status;

- Explaining health-care resources and policies to patients, family and professional staff.

- Helping plan for post-hospital patient needs by arranging for services at another facility or in the home.

- Explaining to patients the epidemiology of diseases, including social environment risk factors.

- Helping the patients and families by providing the needed follow-up care by referral to health-care resources.

- Understanding the social, cultural and religious variables that contribute to patients' responses to illness and their use of health-care resources.

- $\quad$ Providing advocacy and support through appropriate organizations

There are many other services is also done by the medical social worker like close collaboration with other medical and allied health professionals for psychosocial assessment and formulation of welfare plans; provision of tangible assistance such as waiver of medical charges, making recommendations for charitable trust funds etc. They arrange Patient welfare activities are fund raising for under privileged patients'; liaison with philanthropists and other charitable trusts distributing medicines to the needy patients. They also organize periodic recreational activities for patients.

A prime responsibility of Medical Social Worker in under develops country like Pakistan, is to assists the patients, who cannot afford their medications nor have any health insurance. The main aim is to help and facilitate poor patients by providing free medicines or making arrangements for operations. Medical social welfare officers generally with the help of hospital administration, doctors and eminent philanthropist, established Patient welfare society in Hospitals and collecting donation or through Zakat fund ${ }^{\mathrm{i}}$ or from Bait-ul-Mal.

Patient Education is another very important job of social worker. The education Program for mainly focuses on promoting health and good quality of life as well as informing the patients about what is happening to him or her, how it has affected, what are the doctors' plans and how he has to adhere to treatment.

\section{Clinical Social Work Skills:}

Medical social workers are deputed in hospitals and clinics to provide timely psycho-social intervention to patients and their families and help them cope with or solve problems arising from, illness or disability. As a member of the multidisciplinary clinical team, they play an important role in linking up the medical and social services to facilitate a patient's recovery and rehabilitation in the community. Few essential skills are:

- Intake/Screening

- Psychosocial Assessment

- Socio-economic Assessment

- Case Management

- Crisis intervention;

- Establish a relation between patient and doctor

- Discharge Care \& Planning;

- Coordination in care within a team

- Counseling \& Psychotherapy

- Psycho-education

- Medication Facilitation

- Evidence-Based Practice

- Understanding Disease Management Practices

- Professional Competency through Continuing Education

- Ongoing Supervision.

- Financial Assistance,

- Suicide Assessment and Intervention,

- Domestic Violence Intervention,

- Grief and Bereavement Support, Psychological Trauma Support,

- Establish care links for referrals for community resources;

- Patient advocacy for seriously ill patients,

- Home visit \& follow-up and involve in conducting researches.

- Assessing Child Protection / Elder Abuse

In short, there are numbers of responsibilities and functions which perform by a Medical Social Worker in Health care as they distribute services to people encountering health challenges. In Hospitals like Civil Hospital, medical social services projects are not functional due to a shortage of resources. Interestingly on the other hand, as compared to the government, the private sector is offering better health care services in the country. Few 
hospitals in Karachi which are running in private setup, are providing the social welfare assistance services where some qualified medical social welfare or non-professional officers are employed to cater the need of poor and vulnerable patients in private hospital set-up. In many cases, the financial assessment for non-affording or providing counselling services or patient satisfaction is not at a satisfactory level in Private Hospitals.

There have been many changes and difficulties emerging in the Medical Social Work practice in Sind in the field, it is revealed that a number of non-financial constraints have played an equally important contribution in the underperformance of Social welfare officers working in the field. They are de-motivated and distracted from their work by conflicting interests. Weak governance, imbalance of human resource, lack of equitable service delivery, the absence of social safety nets, lack of effective implementation of regulations particularly in a largely unregulated private sector are some of these factors having an adverse impact on their performance in the health sector.

Apart from the problem of Government less investment in the health sector, the practice of Medical Social Work or casework management is in a disappointing situation. There is no provision of on job training in the field, lack of availability of funds, lack of expertise in counseling services, lack of motivation, no reward for hard work no appreciation from seniors and many more challenges are there which makes this job difficult. These issues are complex and multidimensional, requiring an immediate response.

All the stakeholders including the government have neglected social welfare training institutions. It is need of the day to concentrate and establish a social welfare project in all districts in the country especially in hospitals (both public and private). Although, this job is very challenging job, that contributes to every aspect of patient's needs. Medical Social Worker helps the community by assessing their needs and organizes the people to plan programs and provide services in order to meet the needs of the needy patients; create social awareness for needy patients and community in general about the social causes of diseases, their prevention, and amelioration. In short, Medical social work as a profession in Pakistan is able to shape the health care system through creative utilization of research-informed assessment and intervention tools and through the development of innovative models of practice-based evidence

\section{Recommendations:}

The present study suggested the following recommendations are proposed for different stakeholders:

- There is a great need to appoint social workers in different hospitals (in both the public \& private sector) to improve the quality of services for patients' and well-being of Pakistan's population.

- It is suggested that Government of Pakistan may formulate a clear vision and appoints Medical Social Workers in Public Hospital across Sindh province in each District Head Quarter Hospital as per the practices of other provinces of Pakistan. Furthermore, it is necessary to reshape the existing employment structure and design better policies for the future.

- It is recommended that the modification in job Identification may be done and the term of Medical social work may be replaced as" Medical social work practitioner" and social welfare officers need to improve their clinical expertise by practicing social casework methods.

- It is also suggested that the government should take initiatives regarding making a regulatory authority for social workers not only works on protection of the interest of the public by regulating the practice of social workers and promoting ethical and professional practice and licenses for social work practice. The social worker may be bounded to maintain standard operating protocol and code of ethics of the profession as they are professional doing other parts of the world.

- More evaluation research is needed in various health care settings regarding the usefulness of Medical Social work practices in the country. A well-established institutional mechanism is needed for Pakistan's population; by ensuring successful implementation of Medical social work practice.

- The study further suggested that in-services training of Medical Social welfare officers are required for improvement in their performance at national and international level. The federal ministry of health and the Provincial Department of Health and Ministry of Social Welfare must play an important role in this regard and take necessary step in this matter.

- Finally; an updated or revised National Social Welfare Policy is also needed for improving the existing scenario.

Conclusion:It may be concluded that social work is one of the most diverse careers available and it is practiced differently in many settings. There have been many changes emerging in this profession. In pursuance of new possibilities for a better and healthy world, it is important that state must take serious steps for Medical social work profession by incorporating policies and practices that maintain and nurtures' social work perspectives and approaches. Strong emphasis must be given for collaboration between the health professionals when providing services to the patients. More importantly, Association of Professional Medical Social Work Practitioner needs to 
be established in the country as there is neither practices licenses system is exists in country for quality or professional nor professional Association of affiliation social worker it is milieu to operate its professional identity and determine the professional strategy and field related matters or issues effectively and professionally. It is the need of the day for Medical Social work practitioner in the country that they keeping up to date with best practices research, professional ethics and must have practices licenses for clinical practices and professional recognition of this profession in Pakistan.

\section{REFERENCES:}

1. Alston M (2001). Social Work in Health Care settings, Social Work Fields of Practice, Oxford University Press, Australia, page: 99.

2. Ather H. Akbari, Wimal Rankaduwa, and Adiqa K. Kiani (2009) Demand for Public Health Care in Pakistan, The Pakistan Development Review; 48(2):141-153.

3. Bhutta Z.A. (2011). National Nutrition Survey. Islamabad: Ministry of Health, Pakistan.

4. Burki T. (2008). New Government in Pakistan Faces Old Challenges. Karachi: Tropical Medicine Symposium, Aga Khan University and the Royal Society of Tropical Medicine.

5. Cabot, R.C. (1928). Hospital and Dispensary Social Work. Chicago: University of Chicago Press.

6. Commission on Social Determinants of Health (CSDH) (2008). Closing the Gap in a Generation: Health Equity through Action on the Social Determinants of Health (SDOH). Geneva: World Health Organization. Available online at: http://www.who.int/social_determinants/thecommission/finalreport (accessed 21 August 2018).

7. Council on Social Work Education (2006). Educational policy and accreditation standards [Online]. Retrieved from http://www.cswe.org

8. Closing the gap in a generation: Health equity through action on the social determinants of health: $(\mathrm{CSDH})$ WHO, 2008. https://www.who.int/social_determinants/thecommission/finalreport/en/ Accessed on 14August 2018.

9. Dastur, R., (1974), Quarter Century of Medical Social Work, Social Welfare; legend and legacy, Silver Jubilee Commemoration Volume of Indian Council of Social welfare. Edited; B. Chatterjee \& S. D Gokhale. Bombay Popular Prokashan.

10. Dubois, Brenda and K.M.Karle,(2005).Social Work: An Empowering professional, fifth edition, Pearson. Allay and Bacon: pp.51-52.

11. Diedrich J. and Spivak C (2015). Professional group calls for background checks on social workers. Milwaukee Journal Sentinel, 17 June 2018 www.jsonline.com /watchdog/watchdogreports/professionalgroup-calls-forbackground-checks-on-social-workers-b99520971z1-307988751.html (Accessed on 19 June 2018).

12. Government of Pakistan (2010). Health Facts. Islamabad: Ministry of Health.

13. Government of Pakistan (1993). Planning Division, Islamabad, $8^{\text {th }}$ Five Year Plan (1993-98); p.377-379.

14. Government of Pakistan (2001). Ministry of Health, An Overview of the Health Sector: The Way Forward. Islamabad, Pakistan: Multi Donor Support Unit; 20

15. Government of Pakistan (2009). PSLM- 2004-05, 2007-08-Pakistan Social and Living Standards Management Survey. Islamabad: Federal Bureau of Statistics.

16. Gehlert S, Browne T, editors. Handbook of Health Social Work. 2nd ed. Hoboken, NJ: Wiley; 2012. pp.3-19

17. Gitterman A. \& Germain C.B. (2008). The life model of social work practice: Advances in theory and practice, (3rd ed.). New York: Columbia University Press.

18. Hawk, M., Ricci, E., Huber, G., \& Myers, M. (2015). Opportunities for social workers in the patient centered medical home. Social Work in Public Health, 30, 175-184.

19. Hepworth, Dean H., Ronald H. Rooney, Jo Ann Larsen.(2002), Direct social work practice : theory and skills, ( $6^{\text {th }}$ ed) Australia; Pacific Grove, CA: Brooks/Cole-Thomson Learning, p 45.

20. Hutchison, Elizabeth D., (1987) Use of Authority in Direct Social Work Practice with Mandated Clients: $\begin{array}{lllll}\text { Social Service } & \text { Review, } & \text { Vol. } & \text { 61(4), } & \text { pp. }\end{array}$ https://www.jstor.org/stable/30011927?seq=1\#page_scan_tab_contents (Accessed on Nov 2018)

21. Hussein, S. (2011). Social work qualifications and regulation in European Economic Area (EEA). London, Kings College, London University. $\quad$ www.kcl.ac.uk/sspp/policyinstitute/scwru/pubs/2011/hussein2011eea.pdf(Accessed on 31 January 2018).

22. Iwasaki, K. (2001). Certification systems of social workers and enhancement of the profession: Japanese experience. Developing professional social work registration/licensing and education, Singapore, IFSW Asia Pacific Region.

23. Jones, D. N. (2007). "News and views from IFSW - Renewed global interest in the profession." International Social Work 50 (6): 859-861.

24. Jones D (2018) Regulation of Social Work and Social Workers in the United Kingdom Birmingham: BASW 
https://www.basw.co.uk/system/files/resources/Social\%20Work\%20Regulation\%20-

\%20Contexts\%20and\%20Questions.pdf (Accessed Feb 2019)

25. Jaros, Stephen. (2007). Meyer and Allen Model of Organizational Commitment: Measurement Issues. ICFAI Journal of Organizational Behavior. 6. 7-25.

26. Khurshid Khowaja (2009). International Perspectives: Healthcare Systems and Care Delivery in Pakistan, Journal of Nursing Administration, Volume :39 number 6 pp:263-265.

27. Keefe, B., Geron, S. M., \&Enguidanos, S. (2009). Integrating social workers into primary care: Physician and nurse perceptions of roles, benefits, and challenges. Social Work in Health Care, 48, 579-596.

28. Keefler., J. Duder, Lechman, C.,(2001); Pridicting length of stay in an acute hospital; the role of psychosocial problems.Soc Health Care 33:pp 1-16

29. Lashari, T (2004). Pakistan's Health Policy Quest for a vision. Islamabad: The Network.

30. Leung, J. (2001). Hong Kong Social Workers Registration Board: code of practice for registered social workers. Developing professional social work registration/licensing and education, Asia-Pacific Social Work Regional Conference, Singapore.

31. Lim, S.S., Vos, T., Flaxman, A.D., Danaei, G., Shibuya, K., Adair-Rohani, H., Amann, M.(2012) 'A Comparative Risk Assessment of Burden of Disease and Injury Attributable to 67 Risk Factors and Risk Factor Clusters in 21 Regions, 1990-2010: A Systematic Analysis for the Global Burden of Disease Study 2010', The Lancet 380 (9859):2224-60.

32. http://www.thelancet.com/journals/lancet/article/PIIS0140-6736\%2812\%2961766- 8/abstract (Retrieved on October 2018)

33. Marmot, M. (2010) 'Fair Society, Healthy Lives'. Available on http://www.instituteofhealthequity.org/projects/fair-society-healthy-lives-the-marmot-review (accessed 21 August 2018).

34. Malik and Sarfaraz (2012). Pakistan Journal of Commerce and Social ScienceVol. 6 (1), pp. 210-215.

35. Ministry of Finance, Government of Pakistan (2012) Economic Survey of Pakistan (ESP) 2011-12.

36. Mohammad Khalid (1982). The Study of Social Work in Pakistan. Karachi. Kifayat Academy.pp.1-13.

37. Mohammad Khalid (2011), Social Work Theory and Practice: with Special Reference to Pakistan, $7^{\text {th }}$ Edition, Kifayat Academy, pp.34-36.

38. McNabb, D. J. and M. Connolly (2017). "The relevance of Global Standards to social work education in Australasia" International Social Work,http://journals.sagepub.com/doi/abs/10.1177/0020872817710547 (Accessed on 10 July 2018)

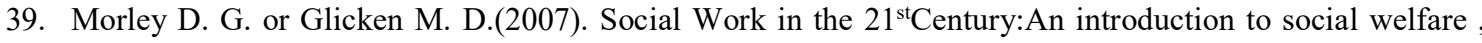
social issues, and the profession, Sage Publications, Inc. California, United State of America .p.g:33.

40. Moniz, C., \& Gorin, S. (2010). Health and mental health care policy - A Biopsychosocial perspective. 3rd edition. Boston, MA: Allyn \& Bacon. Part 5 New direction for health and health policy

41. Mossialos, E., A. Djordjevic, R. Osborn, and D. Sarnak (eds.), International Profiles of Health Care Systems, The Commonwealth Fund, May 2017.https://www.commonwealthfund.org/sites/default/files/documents/media_files_publications_fund_rep ort_2016_jan_1857_mossialos_intl_profiles_2015_v7.pdf(Accessed on Sept 20 2018)

42. Mikkonen, J \& Raphael D, (2010). Social Determinant of Health :The Canadian Fact http://thecanadianfacts.org/the_canadian_facts.pdf

(Accessed on Sept 2018)

43. Nayor, R. (2001). Developing professional social work registration/licensing and education. Social Work leadership and development workshop, Sinagpore, IFSW Asia Pacific Region.

44. Okoye, U. O. (2013). Trends and challenges of social work in Nigeria. In Becoming a social worker: global narratives. V. E. Cree. Abingdon, England. Routledge: 149 onwards.

45. Poullier JP, JP, Hernandez P, Kawabata K, (2003). "Patterns of global health expenditures: results for 191 countries. In: Murray CJL, Evans DB, eds. Health Systems Performance Assessment: Debates, Methods and Empiricism". Geneva, Switzerland: World Health Organization. P :51http://whqlibdoc.who.int/publications/2003/9241562455.pdf Accessed December 2018

46. Palattiyil, G., D. Sidhva and M. Chakrabarti, Eds. (2015). Social work in a global context: Issues and challenges. London, Routledge.

47. Rehmatullah, Sherin, (2002) "Social Welfare in Pakistan". Oxford University Press, Karachi, page :313

48. Stephanie Tuters (2012) Wilkinson, R., \& Pickett, K. (2009). The Spirit Level: Why More Equal Societies Almost Always Do Better. London: Allen Lane., Leadership and Policy in Schools, 11:1, 129134, DOI: $10.1080 / 15700763.2011 .577928$ p 131

49. Stanhope, V., Videka, L., Thorning, H., \& McKay, M. (2015). Moving toward integrated health: An opportunity for social work. Social Work in Health Care, 54, 383-407

50. Sanjay Bhattacharya(2008) Social Work psycho-Social and Health Aspects, Deep \&Deep Publication (p)Ltd, 
New Dehli, India.p.g:12

51. Sachiti, R. (2012). "Zimbabwe: Cracking whip on unregistered social workers" The Herald, (23 February 2012).http://allafrica.com/stories/201202230226.html(Accessed on 28 February 2018)

52. Shariff KM. (2001). Pakistan Almanac 2001-2002. Essential Data on Pakistan. Pakistan: Royal Book Company, p.g: 201-213.

53. Siddiqi S., Hamid S., Rafique G., Chaudhry S.A., Ali N., Shahab S. \& Sauerbon R. (2002). Perception practices of Public and private health care providers in Attock District Of Pakistan, International journal of planning and management.Vol:17 pp:23-40.

54. Talentia (Finland) (2016). "Professional practice rights for social welfare professionals". www.talentia.fi/en/talentia/news/professional_practice_rights_for_social_welfare_professionals.8548.news (Accessed on 18 April 2018).

55. UNICEF (1996). The state of the World Children 1996.Bellamy C eds. Oxford University Press

56. Volland P., Berkman, B., Phillips, M., \& Stein, G. (1997). Social work education for health care: Addressing practice competencies. Social Work in Health Care Journal, 37(4), 1- 17.

57. Whitaker, T., Weismiller, T., Clark, E., \& Wilson, M. (2006). Assuring the sufficiency of a frontline workforce: A national study of licensed social workers. Special report: Social work services in health care settings. Washington, DC: National Association of Social Workers. pp. 4.

58. Wilkinson, R., \& Pickett, K. (2009). The Spirit Level: Why More Equal Societies Almost Always Do Better. London: Allen Lane.

59. Whitaker, T., Weismiller, T., Clark, E., \& Wilson, M. (2006). Assuring the sufficiency of a frontline workforce: A National Study of Licensed Social Workers. Special Report: Social work services in health care setting. Washington, DC: National Association of Social Workers, pp. 9.

60. WHO (2010). The Country Profile, Pakistan, Geneva:WHO.

61. Wing P. \& Salsberg E. (2002). How trends shape the work force today and tomorrow. Journal of AHIMA, 73(4), 38-45.

62. World Bank (1998). Raising a healthier population, South Asia Brief.49-54:27(1)

63. Zaidi S.A.(1988).”Health System of Pakistan'. The Research Forum:3:pp,110-133

Online Resources:

https://www.casw-acts.ca/sites/default/files/attachements/casw_history.pdf 